\title{
Pequena Crónica Arqueológica *
}

\section{Concentração e Falência}

A concentraçâo: a nossa ciência bipolar usa uma série de termos estreitamente associados aos seus opostos [1]. Enquanto a palavra condensação, num contexto próximo, admite como contrário dispersão, a palavra concentração opõe-se mais naturalmente a diluição.

Deve realçar-se um deslocamento após o período de 1750 a 1850 , durante o qual o vocábulo concentração designava apenas «a operação pela qual se aproximam, num menor volume, as partes de um corpo dispersas num fluído» [2], até ao nosso sentido moderno, o de uma quantidade de matéria por unidade de volume. Isto implica um pleonasmo de cada vez que se fala dum aumento de concentração, visto que, no sentido original, só existe concentração.

Outra particularidade: em francês como em inglês, o sentido químico que levanta a questão e o sentido figurado, psicológico se assim se quiser designar, são aproximadamente contemporâneos [3-5]. Depois de ter reunido estas citações [3-5], impôs-se-me a ideia de que elas remetem directamente para uma das obras-primas de Balzac, «A Procura do Absoluto» [6] que, além do mais, tem um químico como personagem central. Reli esse texto, simultaneamente pesado e denso.

«A Procura do Absoluto» data de 1834. Segundo Louis Lambert, é a narração de «o pensamento consumindo o pensador» [7].

A personagem Balthazar Claës, rico proprietário de Douai, prendeu-se à química com uma tal paixão que abandona os seus e esbanja o património familiar. A ruína é evitada precisamente pela sua filha mais velha, Marguerite, que assume a gestão dos seus negócios. Mas ele enlouquece e morre, vítima do «duelo com o Desconhecido» [8].

Que procura Balthazar? Ele persegue o sonho duma química una.

$\mathrm{Na}$ época em que Balzac escreve, os 33 elementos da lista ordenada por Lavoisier, já eram mais de 50. Balthazar Claës procura o princípio único subjacente: «Esses 33 corpos têm um princípio comum, modificado outrora pela acção de uma potência hoje extinta, mas que o génio humano deve fazer reviver. Pois bem, suponhamos por um momento que essa potência é despertada; teríamos então uma química una» [9]. Balthazar procura a substância primordial ou fundamental cujas múltiplas transformações constituem o mundo sensível: «Vós reconhecestes como eu, que a goma arábica, o açúcar e o amido reduzidos a pó dão uma substância absolutamente semelhante, e na análise um mesmo resultado qualitativo» [10]; «A procura do absoluto, princípio pelo qual grãos, absolutamente semelhantes, dão por vezes cálices brancos, outras cálices amarelos! fenómeno aplicável aos bichos da seda que, alimentados das mesmas folhas e constituídos sem diferenças aparentes, fazem uns seda amarela e outros seda branca; enfim, princípio aplicável ao próprio homem que, muitas vezes, tem legitimamente filhos diferentes do pai e da mãe» [11]. É o caso da filha de Balthazar, Marguerite, que «por um capricho que os psicológos ainda não explicaram, não tinha nenhum traço da mãe nem do pai» [12].

Haveria então uma substância única no seio dos corpos simples: também a uma linhagem familiar se transmite esse Absoluto - que nós chamamos agora, depois da revolução mendeliana, património genético -: «uma substância comum a todas as criações, problema oferecido pelo Absoluto e que me pareceu solúvel» [11].

A um opõe-se múltiplo: no tempo de Balzac os químicos descobrem com espanto e respeito, a imensa proliferação das espécies químicas. «Que abismo para a razão humana! gritou Balthazar, levantando as mãos e juntando-as num gesto desesperado. Uma combinação de hidrogénio faz surgir pelas suas dosagens diferentes, num mesmo meio e num mesmo princípio, múltiplas cores cada uma das quais constitui um resultado diferente» [13]. Eis um convite para a meditação sobre as cores mencionadas em «A Procura do Absoluto».

Trata-se principalmente do amarelo e do branco que se opõem como duas virtualidades inconciliáveis (ver acima [11]).

Pode ler-se o romance como uma mudança, uma verdadeira viragem do amarelo para o branco: o amarelo do ouro convertido pela actividade de Balthazar em fumo; e não só, um vez que as pesquisas de Claës têm como resultado, mais ou menos fortuito, a formação de um «diamante branco octaédrico» [14], pela aç̧ão da pilha de Volta sobre o sulfureto de carbono.

Balthazar é um homem prematuramente envelhecido, consumido pela sua obsessão: «por vezes os olhos tomavam uma cor vítrea, parecia que a vista se revirava e penetrava no seu 
interior» [15]; «a imobilidade do seu olhar branco e vazio» [16].

Luzes e cores abundam na descrição do laboratório, passagem crucial que é preciso citar na totalidade. «Balthazar não descia. Cansada de o esperar, Marguerite subiu ao laboratório. Entrando, viu o pai no meio de uma sala imensa, fortemente iluminada, guarnecida de máquinas e objectos de vidro cheios de pó; aqui e ali, livros, mesas cobertas de produtos etiquetados, numerados. Por todo lado a desordem proveniente da preocupação do sábio e dos hábitos flamengos. O conjunto dos balões de vidro, das retortas para destilação, dos metais, das cristalizações fantasticamente coloridas, escantilhões presos nas paredes ou lançados aos fornos, tudo era dominado pela figura de Balthazar Claës que, sem camisa, os braços nús como os de um operário, mostrava o peito coberto de pelos embranquecidos como os seus cabelos.

Os olhos estavam horrivelmente fixos numa máquina pneumática. O recipiente desta máquina era forrado por uma peça constituída por duplas lentes convexas, cheia de álcool e que concentrava os raios de sol que entravam então por um dos compartimentos da rosácea do sotão. O rectipiente cuja parte inferior estava isolada, comunicava através de fios com uma imensa pilha de Volta. Lemulquinier [17] ocupado a fazer mover o suporte da máquina montada sobre um eixo móvel, para que as lentes permanecessem perpendiculares aos raios solares, levantou a face negra de poeira e disse: Ah! A menina não se aproxime!

$\mathrm{O}$ aspecto do pai que, quase ajoelhado diante da máquina, recebia perpendicularmente a luz do sol, e cujos cabelos grisalhos pareciam fios de prata, o crâneo com bossas, a cara contraída por uma espera angustiosa, a singularidade dos objectos que o envolviam, a obscuridade em que se encontravam as partes daquele vasto sotão onde emergiam máquinas bizarras, tudo contribuía para perturbar Marguerite que pensou com terror: «Meu pai é louco!» Aproximou-se dele e disseIhe ao ouvido:

- Mande embora Lemulquinier.

- Não, não, minha filha, tenho necessidade dele, espero o resultado de uma bela experiência nunca antes imaginada. Tenho os meios de submeter os metais, num vácuo perfeito, aos raios solares concentrados e a correntes eléctricas. Vê tu, por um momento, a acção mais enérgica, de que um químico pode dispor, vai manifestar-se, e só eu...» [18].

Retomemos pela ordem inversa estas duas últimas frases. $\mathrm{O}$ reagente que Balthazar Claës quer usar não é mais do que a Energia [19, 20]; em condições demiúrgicas - Prometeu ou Ícaro - um ambiente impróprio para a vida. Impróprio para a vida como o é o gás azoto, no sentido etimológico. E Balthazar Claës quer decompor o azoto, a fim de que os elementos primordiais sejam reduzidos a três: carbono, hidrogénio e oxigénio. «As naturezas orgânicas e inorgânicas assentariam muito provavelmente sobre quatro princípios e, se nós conseguíssemos decompor o azoto que devemos considerar como uma negação, só teríamos três» $[9,21]$.

«Submeter os metais, num vácuo perfeito, aos raios solares concentrados e a correntes eléctricas» [18], não seria produzir as condições necessárias à génese de uma obra, de um pensamento? Não esqueçamos que Balzac escreveu em Louis Lambert, um livro um pouco semelhante ao «A Procura do Absoluto»: «O nosso cérebro é a máquina onde transportamos o que as nossas diversas organizações podem absorver de matéria etérea, base comum de várias substâncias conhecidas sob os nomes impróprios de electricidade, de calor, de vazio, de fluído galvânico e magnético, etc., e de onde ela sai sob forma de pensamento» [22]?

E de onde vem esta "matéria etérea» [22], esta «acção mais enérgica» [18], esta concentração de luz, de calor, de vazio, de fluído galvânico e magnético: ela evoca o misticismo filosófico de Swedenborg [23], a tradição newtoniana, e também a escola científica dominante na época de Napoleão [24].

Uma leitura histórica de «A Procura do Absoluto» parece pertinente. Balzac tem o cuidado de inserir os acontecimentos no quadro histórico - período de 1775 a 1833 - , imediatamente anterior à feitura do livro -: não é um acaso se a felicidade conjugal dos esposos Claës dura até cerca de 1810 [27] e que um retorno do romance coincida com a retirada da Rússia [30].

Hipótese: o embranquecimento, a passagem do amarelo ao branco acima evocada, traduziria uma nostalgia balzaquiana pelas abelhas de ouro imperiais face às flores de Liz que as substituiram na Restauração? Penso que se pode prolongar ainda mais para trás esta melancolia saudosista do autor e entender que não se limita apenas ao Primeiro Império: com efeito, abundam as referências em relação ao reinado de Luis XIV, o Rei Sol [32]. «A Procura do Absoluto» não será um pouco a saudade do poder absoluto do monarca que concentrou todos os poderes nas suas mãos?

«A Procura do Absoluto» é bem o romance da concentração, de todas as concentrações: riquezas [34] na casa dos Claës; heranças culturais (Países Baixos, Espanha) na Flandres onde se encontra esta habitação; concentração dos raios solares na aparelhagem de Balthazar Claës, e também no pátio da casa dos Claës: apesar de se situar em Douai pode ser quente como um forno [35]; concentração do carbono que cristaliza em diamante [14,36]; e depois, sobretudo, concentração de Balthazar Claës sobre as suas ideias e as suas pesquisas [3-5].

A concentração opõe-se à diluição, à dispersão, mas também a ela conduz ou pelo menos the cede o lugar: pode-se dizer, com efeito, que a exclusiva concentração de Balthazar sobre a química é a causa directa da decomposição e da dispersão da sua fortuna. No entanto, esta concentração, certamente patológica, não pode ser qualificada de monomaníaca: Claës experimenta fascinação tanto pelo um como pelo triplo; pelo branco e pelo amarelo; pela decomposição do azoto e pela síntese do diamante.

Todas estas concentrações são duplas. Impõe-se uma explicação: na arquitectura da casa como na estrutura da família Claës, com dois rapazes e duas raparigas [37], há desdobramento.

No livro abundam episódios ou notas, que são repetições, verdadeiros ecos de passagens anteriores. Exemplos: $\mathrm{O}$ avô Van Claës tinha defendido a independência de Gant contra Carlos V; depois Balzac esquematiza a rivalidade entre a nobreza e a burguesia, em Douai, no momento da revolução de 1830; Balzac qualifica de cinzento-castanho o amor entre Marguerite e Emmanuele [38], à imagem das cores da Flandres descritas nas primeiras páginas do livro. 
$\mathrm{O}$ dispositivo experimental de Balthazar Claës tem duas fontes de energia, solar e eléctrica [18]. Também o romance é centrado em duas personagens: os esposos Claës, até à morte de Josephine - cujo diminutivo (Pepita) dá uma cor dourada (a pepita e a Espanha) a esta primeira parte -; depois, na segunda parte, o romance centra-se em Balthazar e sua filha Marguerite, de nome bem escolhido, pois ela representa a própria candura.

Balthazar, lar solar, queima tudo o que toca, enquanto Marguerite, lar eléctrico, acumula dinheiro como uma pilha acumula electricidade.

Balthazar Claës é excêntrico em relação ao seu enquadramento na alta burguesia flamenga. É um excêntrico. Mas o que é um excêntrico? Segundo um dicionário do tempo de Balzac [40] «diz-se de dois ou vários círculos que se entrecruzam e que têm centros diferentes». Esta definição geométrica [40] resume maravilhosamente o episódio bastante singular no qual Marguerite, não só afasta o notário Pierquin [41] que a corteja, como, por outro lado, $o$ arrasta deliberadamente para a órbita da sua irmã Félice que ele desposará. A família Claës é constituída por dois agentes económicos, por dois centros, o pai perdulário (centrífugo) e a filha que reconstitui um património e vela por um pequeno mealheiro (centrípeta). Assim se explica a separação do pai e da filha a fim de evitar que ele interfira mais na sobrevivência precária da fortuna familiar [42]. Ele é expulso para longe, deslocado do seu centro, como consequência da sua própria excentricidade, duma espécie de duplicidade na qual cai sem o querer, abandonando a mulher que, no entanto, adora.

Balzac qualifica a luta de Balthazar consigo mesmo de «duelo com o Desconhecido» [8] porque a personagem que criou está profundamente dividida, verdadeiramente dualizada. O que significa que Balzac a desdobrou: o ajudante de laboratório, Lemulquinier, torna-se tão apaixonado e impaciente como o seu mestre, com o qual se identifica e quase se confunde; ele é a sua réplica, o eco vivo [44].

Acabo de fazer alusão a esta figura geométrica bifocal que é a elipse, como uma das chaves do romance. Mas a elipse é igualmente figura de estilo «devido à actividade impetuosa do nosso espírito, que gostaria de se fazer compreender instantaneamente, e comunicar o pensamento tão rapidamente quanto é concebido" [45].

Não se pode aproximar esta definição do retrato de Balthazar Claës, cujos «olhos de um azul claro e rico, tinham a vivacidade brusca que se nota nos grandes investigadores de causas ocultas» $[46,47]$.

Balthazar Claës ou Balzac? Tal como Louis Lambert [49], Balthazar Claës é o pensamento fulgurante ou elíptico que consome o pensador, é a obra - a Grande Obra mesmo - contra o êxito material; é o sucesso póstumo contra a incompreensão encontrada enquanto vivo.

$\mathrm{O}$ nome Balthazar Claës dificilmente dissimula o de Balzac do qual tem o mesmo «Z» maléfico [50-52].

"A Procura do Absoluto» é sem dúvida, o romance da concentração e da decomposição.

Quanto às outras hipóteses que avancei: projecção da personalidade de Balzac; heliocentrismo; trajectórias elípticas; passagem do amarelo ao branco; nostalgia do absolutismo real e prenúncio implícito do século XIX como o século da Energia, da sua produção e do seu transporte, com «o advento da máquina a vapor, dos caminhos de ferro e da electricidade» [53]; passagem dos cientistas do Antigo Regime, amadores esclarecidos detentores de fortunas pessoais, à actual geração de cientistas que recebem uma verdadeira formação profissional. Todas estas leituras possíveis do mesmo texto atestam a sua genial vitalidade [54].

\section{Referências e notas}

[1] Por exemplo: união/separação; associação/dissociaçâo; ligação/ruptura (ou clivagem); conexão/desconexão; fusão/fissão; síntese/análise; adição/ eliminação (ou fragmentação); agregação/desagregação; composição/decomposição; localização/deslocalização.

[2] Nouveau Vocabulaire de I'Academie Française. L. Aubanel, Avignon, 1822 , artigo "concentration».

[3] "Concentramo-nos num estudo, todas as vezes que a ele nos limitamos sem permitir a interferência de nenhum outro", Condillac, Dictionnaire des Synonymes, Oeuvres Philosophiques, G. Le Roy, ed., Presses Universitaires de France, Paris.

[4] «Concentrar as suas afeiçôes num só objecto; Homem concentrado em si mesmo, com quem não se comunica e que não deixa perceber o que the vai na alma», referência [2], artigo «concentrer».

[5] *Trevas e silêncio produzem a serenidade da mente e a concentração de ideias», Johnson, 1750, «A evidência de um génio superior é o poder da concentraçāo intelectual», B. R. Haydon, 1846, exemplos extraídos de l'Oxford Compact English Dictionary, artigo "concentração".

[6] Edição utilizada: Hauman, Cattoir et Cie, societé Belge de Librairie, Bruxelas, 1837 [ed. port. A Procura do Absoluto, Livr. Ed. Educação Nacional, Porto, 1937].

[7] Honoré de Balzac, Introduction aux Études Philosophifiques.

[8] Referência [6] pág. 282.

[9] Referência [6] pág. 120-121. O número 53 é extraído de Traité de Chimie de Berzélius, ele mesmo tido como dualista.

[10] Referência [6] pág. 119.

[11] Referência [6] pág. 123-124.

[12] Referência [6] pág. 146.

[13] Referência [6] pág. 111 - Provável alusâo à hipótese de Proust (1816).

[14] Referência [6] pág. 336-337.

[15] Referência [6] pág. 63.

[16] Referência [6] pág. 83.

[17] Ajudante de Laboratório.

[18] Referência [6] pág. 250-251.

[19] «No início era a Energia. Balthazar Claës procura, não a pedra filosofal, mas «o princípio comum da atmosfera», «a substância comum a todas as criaturas, modificada por uma força única»».

[20] «A Procura do Absoluto» é de 1834. No mesmo ano Clapeyron analisou o rendimento da máquina a vapor em Théorie mécanique de la chaleur. As Réflexions sur la puissance motrice du feu de Sadi - Carnot são da mesma época (1824).

[21] Seguindo os desenvolvimentos do número três: «Eis-nos próximo do grande Ternário dos anciãos e alquimistas da Idade-Média de quem nos rimos tanto" [9]; «A adoração pitagórica pelo um, de onde saem todos os números e que representa a matéria una, o número dois, primeira agregação e origem de todas as outras e o número três, que desde sempre configura Deus, isto é, a Matéria, a Força e o Produto; não resumem tradicionalmente o conhecimento confuso do Absoluto? Sthall, Becher, Paracelso, Agrappa, todos grandes investigadores das causas ocultas, tinham por palavra de ordem o trismegisto, que representa o grande ternário; e os ignorantes habituados a condenar a alquimia, essa química transcendente, nẩo sabem que nos ocupamos hoje a justificar as apaixonantes investigaçōes desses grandes homens!

[22] Ver P. G. CASTEX, «L'Univers de la Comédie Humaine», Nova Edição da Pléiade, Gallimard, Paris, vol. 1, 1976.

[23] Do qual uma personagem de «A Procura do Absoluto», Emmanuel de Solis, tem o prenome. Um outro romance de Balzac, «Seraphita», é todo impregnado de Swedenborg.

[24] A pequena expansão da Escola de Arcueil [25], fundada por Laplace e Bertholet, e da qual faziam também parte Poisson, Malus, Gay-Lussac, Biot, 
etc., atribui-se ao dogmatismo da sua doutrina: que tudo queria explicar, desde a afinidade química, o calor, a electricidade, até ao magnetismo, por fluídos imponderáveis e inatingíveis, constituídos por partículas que exerciam mutuamente atracções ou repulsões a curta distância. $\mathrm{O}$ seu período criativoé limitado aproximadamente, por este facto, aos anos imperiais 18001812 [26]. Em «A Procura do Absoluto», Balzac cita os nomes de Bertholet e de Gay-Lussac.

[25] M. P. Crosland, «The Society of Arcueil», Heinemann, London, 1967. [26] J. R. Ravetz, «Scientific Knowledge and Its Social Problems», Claredon Press, Oxford, 1971, pág. 226 e nota [20] desta página.

[27] Balthazar Claës, que tinha aprendido química com Lavoisier em 1783 [28], iniciou a "A Procura do Absoluto" com o oficial polaco que havia instalado em sua casa em 1809 [29].

[28] Referência [6] pág. 38.

[29] Referência [6] pág. 58 e 118.

[30] «Mas o vigésimo nono boletim e as novidades dos desastres da Grandearmada na Rússia e na Beresina eram distribuídos depois do jantar» [31].

[31] Referência [6] pág. 144.

[32] Pelas alusões a personagens ilustres (Fenelon e $\mathbf{M}^{\mathrm{me}}$ Guyon) admiradas [33] por uma personagem do romance e do qual o nome (de Solis), com evidente conotação solar, reflecte-nos o Rei Sol. Este eclesiástico de Solis, é o tio de Emmanuel [23] que desposa Marguerite Claẽs. Num outro registo, os alquimistas transformavam o Adam metálico em sol terrestre.

[33]Referência [6] pág. 170.

[34] Uma centena de quadros dos mestres: Rubens, Ruysdael, Van Dyck, Terburg, Gèrard Dow, Téniers, Miéris, Paul Potter, Wouvermans, Rembrandt, Hobbéma, Cranach, Holbein; assim como uma colecção de tulipas, compõem o ambiente muito colorido que contrasta com o laboratório de Balthazar, do qual Balzac dá uma descrição a «tinta da China», sugerindo vantagens da gravura em relação à pintura [18].

[35] O que corrobora a hipótese de que o modelo da casa Claës se encontrar em Tours, onde se conhece por «casa de Tristan»; P. G. Castex, «L'Univers de la Comédie Humaine», Nova Edição de Pléiade, Gallimard, vol. 1, 1976, p. XXIV.

[36] Referência [6] pág. 91.

[37] Marguerite e Gabriel, ocupam posições de destaque enquanto Félice e Jean desempenham papéis secundários.

[38] Referência [6] pág. 187.

[39] «A ideia do Absoluto tinha passado por tudo como um incêndio», referência [6] pág. 353.

[40] Referência [2], artigo «excêntrico».

[41] Existe como que um eco abafado de Charles Quint, ao qual se opunha um

Van Claës, no nome do notário oportunista Pierquin, que procura aliar-se aos Van Claës.

[42] E por consequência a dependência das crianças, sobretudo Marguerite e Gabriel, duma classe afortunada. Este dinheiro deve servir para os estudos em Paris dos filhos da família, - do herdeiro Gabriel. Este último pode assim entrar na Escola Politécnica. Ora a Escola Politécnica foi o primeiro berço da ciência francesa, a primeira tentativa de organizar uma formação científica regulamentada; o que contrasta com o Antigo Regime, onde os investigadores eram antes de mais amadores distinguidos por fortuna pessoal [43]. Existe uma ruptura sociológica entre Balthazar, homem do Antigo Regime e seu filho Gabriel que representa a nova geração científica.

[43] Ver sobre este assunto, M. Crosland, «The development of a professional career in science in France», Minerva, 13, 38 (1975); Gay Lussac: «uma etapa na profissionalização da ciência», La Recherche, 91, 625 (1978).

[44] E o lugar do livro é Douai, cujo nome poderia evocar tão bem as qualidades intelectuais de Balthazar como o carácter do sinal dois.

[45] Fontanier, «Les figures du discours», 1821-1827, reeditado por Flammarion, Paris, 1968, pág. 308.

[46] Referência [6] pág. 28.

[47] E dos quais a impetuosidade se desvanece «uma carantonha que formava os balaústres», logo que toma a sua mulher nos braços [48]. Esta característica da escultura funciona como alegoria do herói que destrói toda a sua família. [48] Referência [6] pág. 96.

[49] «Tal como Louis Lambert que queria ser um «alquimista do pensamento», Balzac é o alquimista da ficção: produzir ouro a partir de metais-base era trabalho fácil». D. Bellos, «Balzac Criticism in France 1850-1900. The making of a reputation», Claredon Press, Oxford, 1976, pág. 70.

[50] «De um ponto de vista balzaquiano o Z (existente no nome Balzac) é a letra do desvio (ver a novela «Z. Marcas»); aqui mesmo (em a novela «Sarrasine») o Z é a letra inaugural de Zambinella, inicial da castração». R. Barthes, «S/Z», Edição de Seuil, Paris, 1970, Colecção «Points» XLVI, pág. 113.

[51] Balthazar Claës é iniciado em química pelo oficial polaco Adam de Wierzchowitz: o início e o fim do alfabeto; o Z é redobrado. Note-se o nome, o mesmo do primeiro homem, mas também o sujeito da grande obra mineral e metálica. A propriedade de Madame Hanska em Ukraine chamava-se Wierzchownia.

[52] A obsessão do Balthazar pela decomposição do azoto não indicará uma fascinação verbal por parte de Balzac pela palavra «azoto»? - que contém a mesma letra Z tão próxima do sinal dois. Esta azoto «que devemos considerar como uma negação" [9], e que é necessário decompor (traduzir: retirar o Z) para encontrar o Absoluto e aceder à Unidade?

[53] S. Nora e A. Minc, "L'information de la société. La documentation française», Paris, 1978, pág. 11.

[54] É talvez uma das fontes de inspiração da «L'Oeuvre au Noir», de Marguerite Yourcenar, 1968. Existem ainda certamente, algumas semelhanças entre «A Procura do Absoluto» e «Notre Dame de Paris» de Victor Hugo que lhe é anterior (1831).

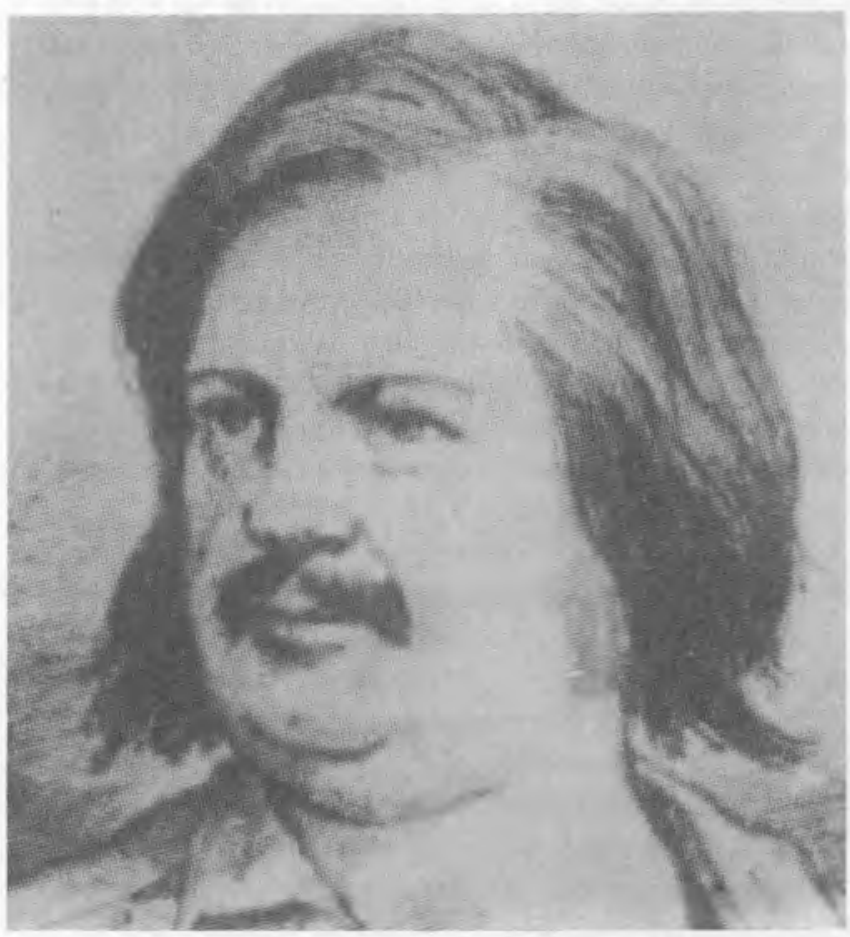

Honoré de Balzac (1799-1850), célebre escritor francês, nasceu em Túrones e é autor da "Comédia Humana" e de uma série de romances notáveis. Na sua obra, Balzac, pelo poder de observaçâo, sentimento da realidade, fecundidade de imaginação e pintura fina e profunda das paixões humanas, faz reviver toda a sociedade do seu tempo. Os seus principais romances sâo: «Eugénia Grandet», «O Tio Goriot», «A Procura do Absoluto», «As Ilusōes Perdidas» $e$ «O Lírio no Vale». 